\title{
Some Background on this New Journal
}

\section{JQ Johnson, University of Oregon Libraries ${ }^{1}$}

It is exciting to be present at the creation of a new journal, and especially the new Oregon Undergraduate Research Journal. Establishing a peer reviewed journal is a substantial undertaking, and the work that the student editors and various UO faculty and staff have put in has been quite impressive.

Planning for a UO undergraduate journal began more than a year ago, in June 2010, with meetings among interested faculty and administrators. In that early period there were more questions than answers: Should such a journal be student- or faculty-edited? Should it be peerreviewed, and should it be open access? Which departments on campus would take responsibility for sponsoring the journal? How would it relate to other UO publications that feature student research such as the UO McNair Journal or to discipline specific academic journals that might be alternatives for the publication of student work? Etc.

Answers to most of the questions came quickly. Whether this should be a student-produced publication became a non-issue when a group of students came forward and announced that they were planning an undergraduate journal. It's not clear if the administrators co-opted the students or vice versa, but a synergistic collaboration quickly developed. The outcome was a student edited and managed publication with support and sponsorship from the Office of the Vice President for Research and the UO Libraries, plus encouragement and assistance from Student Affairs, Undergraduate Studies, and the Clark Honors College.

Whether this new publication should be a peer-reviewed journal wasn't hard either, since the student editors were clear in their resolve to focus this new journal on the highest quality UO student work. Peer review works well in mainstream academic scholarly publication, and the editors realized - correctly - that by mirroring the process of other academic journals they had the best chance of identifying the most outstanding undergraduate research. It provided a great learning experience for the editors, too; it's a good bet that many of them will become professors and maybe edit their own journals or serve on editorial boards in their chosen disciplines.

For the UO Libraries, the new journal was a great opportunity. The library already had an annual Undergraduate Research Award that recognizes undergraduate students who demonstrate skill and creativity using library resources in their research. In addition, the library has a strong commitment to open access - online, free distribution of scholarly work - as a way to take advantage of modern Internet technology, improve scholarly communications, and make scholarship available to a wider public audience than is possible with traditional journals that may only be subscribed to by a handful of academic research libraries. The Oregon Undergraduate Research Journal plans dovetailed nicely with a new library program to serve as 
publisher for UO open access journals using the Open Journal System developed by Simon Fraser University. This journal is the second one published by the UO Libraries, the first being Humanist Studies and the Digital Age (available on the same website as OUR Journal).

All of the participants in OUR Journal are excited about this inaugural issue and looking forward to future issues. We anticipate continued annual publication of high-quality undergraduate research articles, often based on term papers or senior theses. We are also excited by the possibility of taking advantage of technology to widen our net, and to publish student works in the creative and performing arts, multimedia "papers," online computer-based tools that disseminate the results of student programming projects, student-generated datasets, and much more. The core mission will remain, though, to showcase the best University of Oregon undergraduate work.

${ }^{1}$ Note: JQ Johnson is Director, Scholarly Communications and Instructional Support at the University of Oregon Libraries, and leads the library's efforts to serve as publisher for open access journals such as this one. 